Received: 08.05.2018

Revised: 28.05.2018

Accepted: 26.10 .2018

DOI: $10.17804 / 2410-9908.2018 .5 .127-139$

\title{
ON THE EVOLUTION OF THE MICROSTRUCTURE AND PHASE COMPOSITION IN THE FRICTION STIR WELDED AA 2024 ALLOY
}

\author{
K. N. Kalashnikov ${ }^{\text {a)* }}$, T. A. Kalashnikova ${ }^{\text {b) }}$, S. V. Fortuna ${ }^{\text {c) }}$, A. V. Vorontsov ${ }^{\text {d) }}$, \\ V. A. Krasnoveykin ${ }^{\mathrm{e}}$, A. V. Chumaevskii ${ }^{\mathrm{f}}$ \\ Institute of Strength Physics and Materials Science, SB RAS, \\ 2/4 Akademicheskii Ave., Tomsk, 534055, Russian Federation \\ a) (ID https://orcid.org/0000-0002-0286-7156 ; ه sso.spektr.asu@gmail.com ; \\ b) (iD https://orcid.org/0000-0002-0388-4011; $\otimes$ gelombang@ispms.tsc.ru ; \\ c) (iD https://orcid.org/0000-0002-2749-8094; ; s_fortuna@ mail.ru ; \\ d) (ID https://orcid.org/0000-0002-4334-7616; vorontsov.a.583@ gmail.com ; \\ e) (iD https://orcid.org/0000-0003-1405-0597; olodia74ms@yandex.ru ; \\ f) iD https://orcid.org/0000-0002-1983-4385; ; tch7av@ gmail.com \\ *Corresponding author. E-mail: sso.spektr.asu@ gmail.com \\ Address for correspondence: per. Akademicheskii, 2/4, Tomsk, 634055, Russian Federation \\ Tel.: 83822286863
}

The structure formed in thermally hardened aluminum alloys during friction stir welding is studied by optical metallography, SEM, and TEM. As a result, it has been found that the structure of the material in the stir zone is fine-grained, with the mean grain size ranging 3.5 to $5.0 \mu \mathrm{m}$. The presence of several types of secondary phases differing in their mean grain size, structure, distribution in the bulk of the material, and chemical composition has been revealed.

Keywords: friction stir welding, deformable thermally hardenable, aluminum alloy, microstructure, intermetallic compounds, phase composition.

\section{Acknowledgment}

The work was performed within the Program of Basic Scientific Research of the State Academies of Sciences for 2013-2020, line of research III.23, and financially supported by the RFBR, project p a No. 16-48-700652.

\section{References}

1. Boytsov A.G., Kachko V.V., Kuritsyn D.N. Friction stir welding. RITM Mashinostroeniya, 2013, no. 10 (88), pp. 38-44. Available at: http://ritm-magazine.ru/ru/magazines/2013/ritm-10-882013\#page-4142. (In Russian). (Accessed: 25.04.2018).

2. Mironov S.Yu. Formation of grain structure in friction stir welding. Fizicheskaya Mezomekhanika, 2014, vol. 17, no. 1, pp. 103-113. (In Russian).

3. Mironov S.Yu. Crystallographic textures formed during friction stir welding. Fizicheskaya Mezomekhanika, 2014, vol. 17, no. 2, pp. 43-54. (In Russian).

4. $\quad$ Avinash P., Manikandan M., Arivazhagan N., Devendranath Ramkumar K., Narayanan S. Friction Stir Welded Butt Joints of AA2024 T3 and AA7075 T6 Aluminum Alloys. Procedia Engineering, 2014, vol. 75, pp. 98-102. DOI: 10.1016/j.proeng.2013.11.020. 
5. Khodir S.A., Shibayanagi T. Microstructure and Mechanical Properties of Friction Stir Welded Dissimilar Aluminum Joints of AA2024-T3 and AA7075-T6. Materials Transactions, 2007, vol. 48, no. 7, pp. 1928-1937. DOI: 10.2320/matertrans.MRA2007042.

6. Khodir S.A., Shibayanagi T. Microstructure and Mechanical Properties of Friction Stir Welding Similar and Dissimilar Joints of Al and Mg alloys. Transactions of JWRI, 2007, vol. 36, no. 1 , pp. $27-40$.

7. Malopheyev S., Mironov S., Kulitskiy V., Kaibyshev R. Friction-stir welding of ultra-fine grained sheets of $\mathrm{Al}-\mathrm{Mg}-\mathrm{Sc}-\mathrm{Zr}$ alloy. Materials Science \& Engineering A, 2015, vol. 624, pp. 132-139. DOI: 10.1016/j.msea.2014.11.079.

8. GOST 21631-76. Listy iz alyuminiya i alyuminievykh splavov. Tekhnicheskie usloviya [Sheets of Aluminium and Aluminium Alloys. Specifications]. Moscow, Standartinform Publ., 2008, 28 p. (In Russian).

9. Muravyov V.I., Bakhmatov P.V., Melkostupov K.A. On the topicality of studying friction stir welding of high-strength aluminum alloys. Uchenye Zapiski Komsomolskogo-na-Amure Gosudarstvennogo Tekhnicheskogo Universiteta, 2010, no II-1 (2), pp. 110-125. (In Russian).

10. Baranova L.V., Demina L.E. Metallograficheskoye travleniye metallov $i$ splavov: spravochnik [Metallographic Etching of Metals and Alloys]. Moscow, Metallurgiya Publ., 1986, 256 p. (In Russian).

11. Saltykov S.A. Stereometricheskaya metallografiya [Stereometric Metallography]. Moscow, Metallurgiya Publ., 1976, 271 p. (In Russian).

12. OST 134-1051-2010 Svarka friktsionnaya. Tekhnicheskiye trebovaniya $k$ svarnym soedineniyam [Friction Welding. Specification for Welded Joints]. Moscow, 2011, 26 p. (In Russian).

13. Mondolfo L.F. Struktura $i$ svoystva aluminievykh splavov [Structure and Properties of Aluminum Alloys]. Moscow, Metallurgiya Publ., 1979, 640 p. (In Russian).

14. Fortuna S., Kalashnikova T., Kolubaev E. Structural and Phase State Evolution in Friction Drilling on AA2024. In: AIP Conference Proceedings, 2017, vol. 1909, pp. 020055. DOI: $10.1063 / 1.5013736$.

15. GOST 4784-97. Alyuminiy $i$ splavy alyuminievye deformiruemye. Marki. [Aluminium and Wrought Aluminum Alloys. Grades]. Moscow, Izdatelstvo Standartov Publ., 1999, 32 p. (In Russian). 
Подана в журнал: 08.05.2018

УДК 539.25:621.791.14:620.186.12

DOI: $10.17804 / 2410-9908.2018 .5 .127-139$

\title{
К ВОПРОСАМ ЭВОЛЮЦИИ МИКРОСТРУКТУРЫ И ФАЗОВОГО СОСТАВА В МАТЕРИАЛЕ ЛИСТОВОГО ПРОКАТА ИЗ СПЛАВА Д16Т В ПРОЦЕССЕ СВАРКИ ТРЕНИЕМ С ПЕРЕМЕШИВАНИЕМ
}

\author{
К. Н. Калашников ${ }^{\text {a)* }}$, Т. А. Калашникова ${ }^{\text {() }}$, С. В. Фортуна ${ }^{\text {в) }}$, А. В. Воронцов ${ }^{\text {r) }}$, \\ В. А. Красновейкин ${ }^{\text {д) }}$, А. В. Чумаевский ${ }^{\text {e) }}$ \\ Институт физики прочности и материаловедения СО РАН, \\ пр. Академический, 2/4, г. Томск, 634021, Российская Федерация \\ a) (DD https://orcid.org/0000-0002-0286-7156 ; sso.spektr.asu @ gmail.com ; \\ б) (iD https://orcid.org/0000-0002-0388-4011; ; gelombang @ispms.tsc.ru ; \\ в) (iD https://orcid.org/0000-0002-2749-8094; $\otimes$ s_fortuna @ mail.ru ; \\ r) (iD https://orcid.org/0000-0002-4334-7616 ; vorontsov.a.583@ gmail.com; \\ य) (iD https://orcid.org/0000-0003-1405-0597; 인 volodia74ms@yandex.ru ; \\ e) (iD https://orcid.org/0000-0002-1983-4385; $\otimes$ tch7av@ gmail.com \\ *Ответственный автор: sso.spektr.asu @ gmail.com \\ Адрес для переписки: пр. Академический 2/4, 634055, Томск, Российская Федерация \\ Тел.: 8-382-228-68-63
}

Методами оптической, растровой электронной и просвечивающей микроскопии проведены исследования структуры материала, формируемого при сварке трением с перемешиванием деформируемых термически упрочняемых алюминиевых сплавов. В процессе исследований выявлено, что структура материала в зоне перемешивания является мелкозернистой со средним размером зерна от $~ 3,5$ до 5,0 мкм. Показано наличие нескольких типов вторичных фаз, различающихся как средним размером, так и строением, распределением в объеме материала и химическим составом.

Ключевые слова: сварка трением с перемешиванием, термически упрочняемый деформируемый, алюминиевый сплав, микроструктура, интерметаллидные соединения, элементный состав.

\section{1. Введение}

Анализ открытых литературных источников, посвященных сварке трением с перемешиванием (СТП) [1], показывает, что подавляющее большинство исследований посвящено изучению структуры соединений, полученных методом сварки трением с перемешиванием (СТП-соединений) сталей аустенитного класса, чистых металлов, деформируемых алюминиевых сплавов. Для таких материалов обсуждаются механизмы формирования СТП-соединений, структура и текстурные агрегаты [2, 3].

В немногочисленных работах зарубежных авторов посвященных структурным исследованиям СТП термически упрочняемым деформируемым алюминиевым сплавам, например в [4-6], отмечается изменение элементного состава в зонах перемешивания и термомеханического воздействия, а также растворения и повторного выпадения упрочняющих фаз. Однако дисперсность и характер распределения, эволюция элементного и фазового составов упрочняющих фаз не исследуются. Хотя авторы работы [7] детально изучили трансформацию в результате СТП-структуры и фазового состава термически упрочняемого деформиру- 
емого алюминиевого сплава 1570C системы Al-Mg-Sc-Zr в исходном ультрамелкозернистом (УМЗ) состоянии.

Вместе с тем в случае термически упрочняемых деформируемых алюминиевых сплавов для достоверного прогнозирования свойств СТП-соединений необходимо, но недостаточно, учитывать эволюцию только структуры материала в зоне воздействия СТП. Необходимо также учитывать трансформацию фазового состава, дисперсность и распределение упрочняющих вторичных фаз, как в материале соединения, так и в зонах влияния СТП. Возможно, что это является определяющим фактором для решения проблемы формирования равнопрочных СТП-соединений термически упрочняемых деформируемых алюминиевых сплавов.

Цель работы - выявление эволюции микроструктуры и фазового состава материала листового проката термически упрочняемого деформируемого алюминиевого сплава Д16 в процессе сварки трением с перемешиванием.

\section{2. Материал и методы исследования}

Проведены структурные исследования СТП-соединений листового проката марки Д16АТ номинальной толщиной 5,0 мм. Основные технологические параметры СТП представлены в табл. 1. Листовой прокат, использованный в работе, изготовлен в соответствии с требованиями ГОСТ 21631 [8] и в состоянии поставки имеет плакировку алюминием.

В работе [9] для исследования пластического течения металла при СТП листового проката из сплава 2024-Т3 (аналог отечественного сплава Д16Т2) использовали отожженную медную фольгу в качестве маркерного материала. Маркерный материал устанавливали в стык между соединяемыми заготовками непосредственно перед операцией СТП. При последующем металлографическом исследовании авторы выявили характер распределения маркировочного материала в соединении. В представленной работе в качестве маркерного материала использовали плакировку из алюминия, нанесенную на листы проката в процессе его производства и не удалявшуюся с заготовок перед операцией СТП.

Таблица 1 - Технологические режимы сварки трением с перемешиванием

\begin{tabular}{|c|c|c|c|c|}
\hline Материал & $\begin{array}{c}\text { Маркировка } \\
\text { образца }\end{array}$ & $\begin{array}{c}\text { Частота } \\
\text { вращения } \\
\text { инструмента, } \\
\text { мин }^{-1}\end{array}$ & $\begin{array}{c}\text { Скорость } \\
\text { инструмента, } \\
\text { мм/мин }\end{array}$ & $\begin{array}{c}\text { Усилие } \\
\text { прижима, } \\
\text { кгс }\end{array}$ \\
\hline $\begin{array}{c}\text { Листовой прокат } \\
\text { толщиной 5,0 мм } \\
\text { марки Д16АТ } \\
\text { по ГОСТ 21631 [8] }\end{array}$ & № 1 & 500 & 120 & 2000 \\
\cline { 2 - 5 } & № 2 & 1050 & 50 & 1050 \\
\hline
\end{tabular}

Структуру основного металла и СТП-соединений исследовали при помощи металлографического микроскопа МЕТАМ ЛВ-31 при увеличениях до 500 крат и растрового электронного микроскопа Zeiss LEO EVO 50 при увеличениях до 10000 крат.

Металлографические исследования проводили на травленых шлифах, приготовленных в сечениях, перпендикулярных оси СТП-соединений и направлению прокатки основного металла. Для выявления микроструктуры материала травление полированной поверхности металлографических шлифов осуществляли химическим способом реактивом следующего состава [10]: 1 мл плавиковой кислоты $+1,5$ мл соляной кислоты $+2,5$ мл азотной кислоты + 95 мл воды. Измерения размеров зерен производились в указанных областях методом секущих [11]. Направление секущих выбиралось нормально к лицевой поверхности образцов. 
Для исследования микроструктуры и фазового состава методами растровой электронной микроскопии (РЭМ) использовались полированные металлографические шлифы, приготовленные так же, как и для металлографических исследований (кроме завершающей операции химического травления). РЭМ-исследования проводились в основном в режиме обратно рассеянных электронов и дополнительно в режиме вторичных электронов. Кроме того, в процессе РЭМ-исследования производился энергодисперсионный элементный микроанализ вторичных выделений и твердого раствора материала исследования.

\section{3. Результаты и обсуждение}

На рис. 1 и 2 представлены общий вид СТП-соединений листового проката марки Д16АТ и металлографические изображения их структуры в поперечных сечениях соответственно. В процессе СТП по обоим режимам опорным буртом рабочего инструмента на лицевой стороне СТП-соединения полностью снимается поверхностный плакирующий слой. Как следствие, на лицевой стороне соединения формируется грат и грубые заусенцы [12].

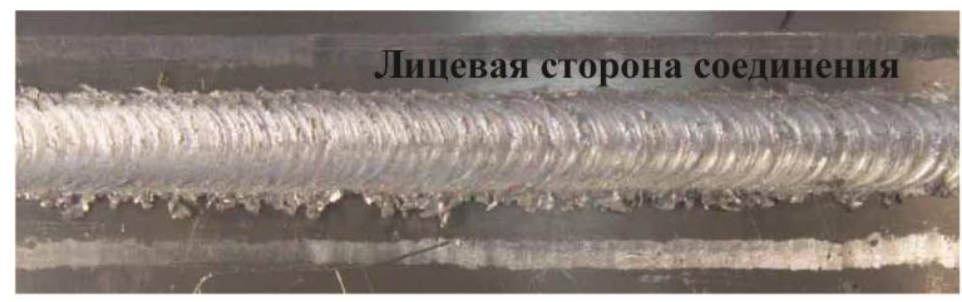

$a$

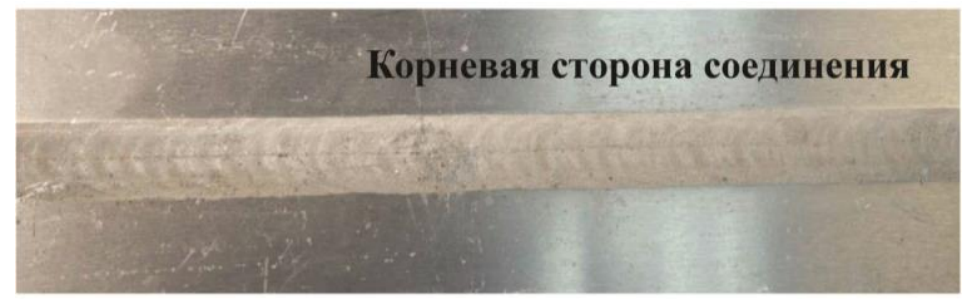

б

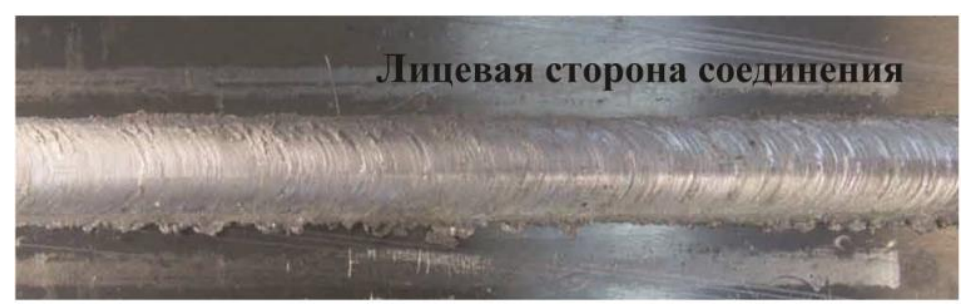

B

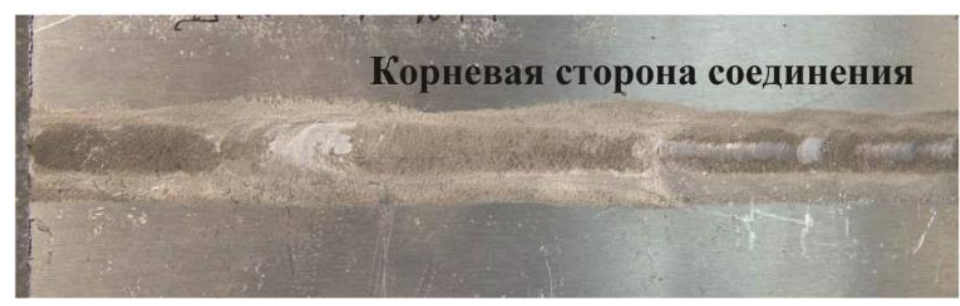

2

Рис. 1. Общий вид СТП-соединений из листового проката марки Д16АТ толщиной 5,0 мм: $a, \sigma$ - образец № $1 ;$,, 2 - образец № 2 
Маркировочный материал со стороны корня соединения проникает в СТП-соединение, локализуясь, в основном, между зоной перемешивания (ядром) и зоной термомеханического воздействия. При этом большему усилию прижима рабочего инструмента соответствует большая глубина проникновения маркерного материала (табл. 1 и рис. 2) и достигает 7/8 толщины СТП-соединения для образца № 1 (рис. 2).

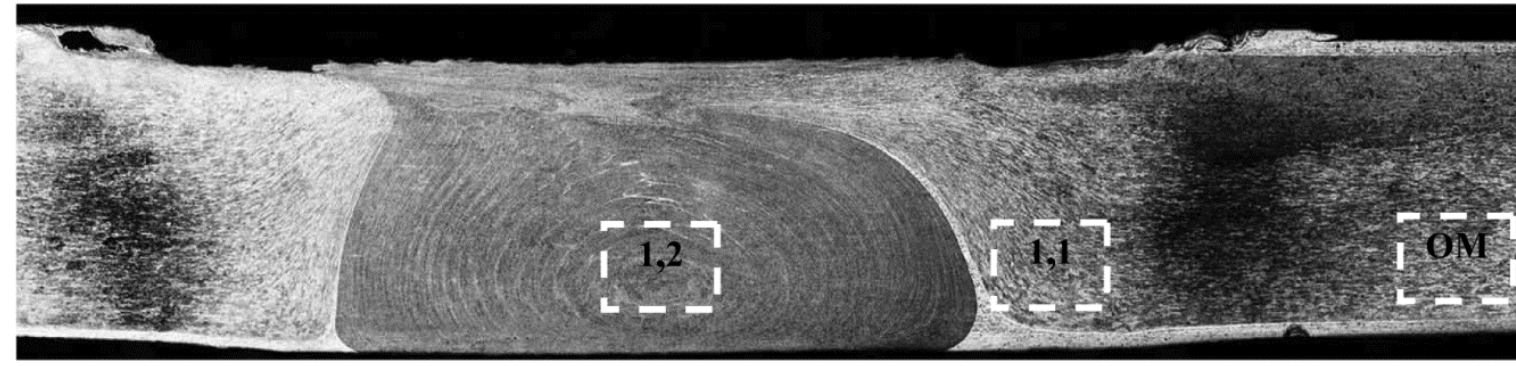

$a$

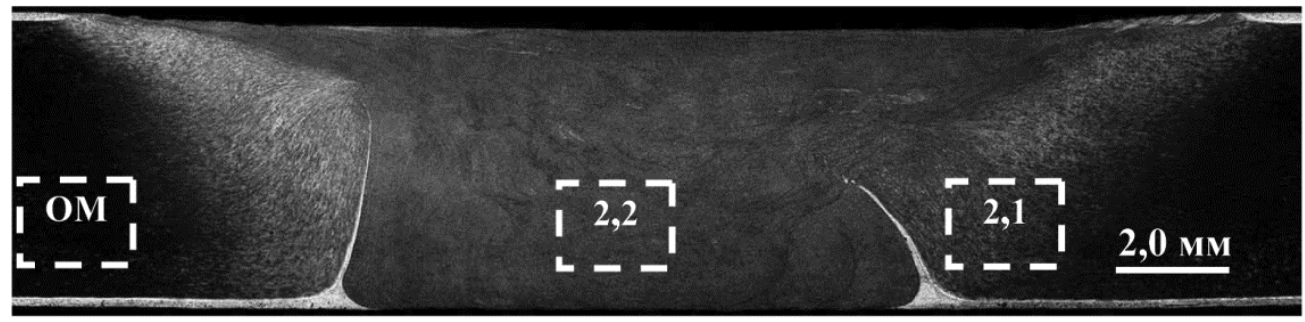

$\sigma$

Рис. 2. Металлографические изображения травленых поперечных макрошлифов СТП-соединений из листового проката марки Д16АТ толщиной 5,0 мм: $a$ - образец № $1 ; \sigma$ - образец № 2

По результатам металлографических исследований проведен анализ среднего размера зерна $\alpha$-Al твердого раствора в основном металле (OM), в зонах термомеханического воздействия (1.1 и 2.1) и зонах перемешивания (1.2 и 2.2) СТП-соединений, полученных по обоим режимам. Соответствующие области, в которых проводились замеры размеров зерен, обозначеныны на рис. 2. Гистограммы на рис. 3 и 4 представляют распределение размеров зерен $\alpha$-Al твердого раствора в материале основного метала и зонах СТП-соединений образцов № 1 и № 2 соответственно. Основной металл вне зоны воздействия СТП в исходном состоянии обоих образцов характеризуется близкими значениями

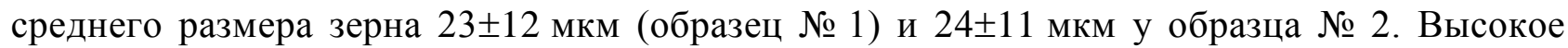
значение среднеквадратических отклонений обусловлено наличием в основном металле небольшой доли зерен крупнее 60 мкм.

Зоны ТМВ образцов № 1 и № 2 значительно различаются зеренной структурой $\alpha$-Al твердого раствора (рис. 3 б и 4 б). СТП по режиму № 1, приводит к уменьшению размера зерна в зоне ТМВ относительно основного металла вне зон влияния СТП на $40 \%$ до среднего значения $13 \pm 15$ мкм. Тогда как в результате СТП по режиму № 2 в зоне ТМВ размер зерна увеличивается на 42 \% (относительно основного металла) и составляет $34 \pm 12$ мкм. Очевидно, что различия в зеренной структуре зон ТМВ образцов обусловлены различиями в технологических параметрах процесса СТП. Технологические параметры по режиму № 2 отличаются от режима № 1 большей частотой вращения рабочего инструмента (в 2,1) и меньшими скоростью подачи инструмента (в 2,4 раза) и усилием прижатия инструмента (в 1,9 раза) (табл. 1). Из сопоставления комбинации этих технологических параметров с результатами исследования зеренной структуры 
в зоне ТМВ следует, что сочетание высокой частоты вращения рабочего инструмента с низкой скоростью процесса сварки (подачи рабочего инструмента) является определяющим фактором, обусловливающим повышение температуры в зонах влияния СТП. Повышенная температура приводит к росту размера зерна в указанных зонах.

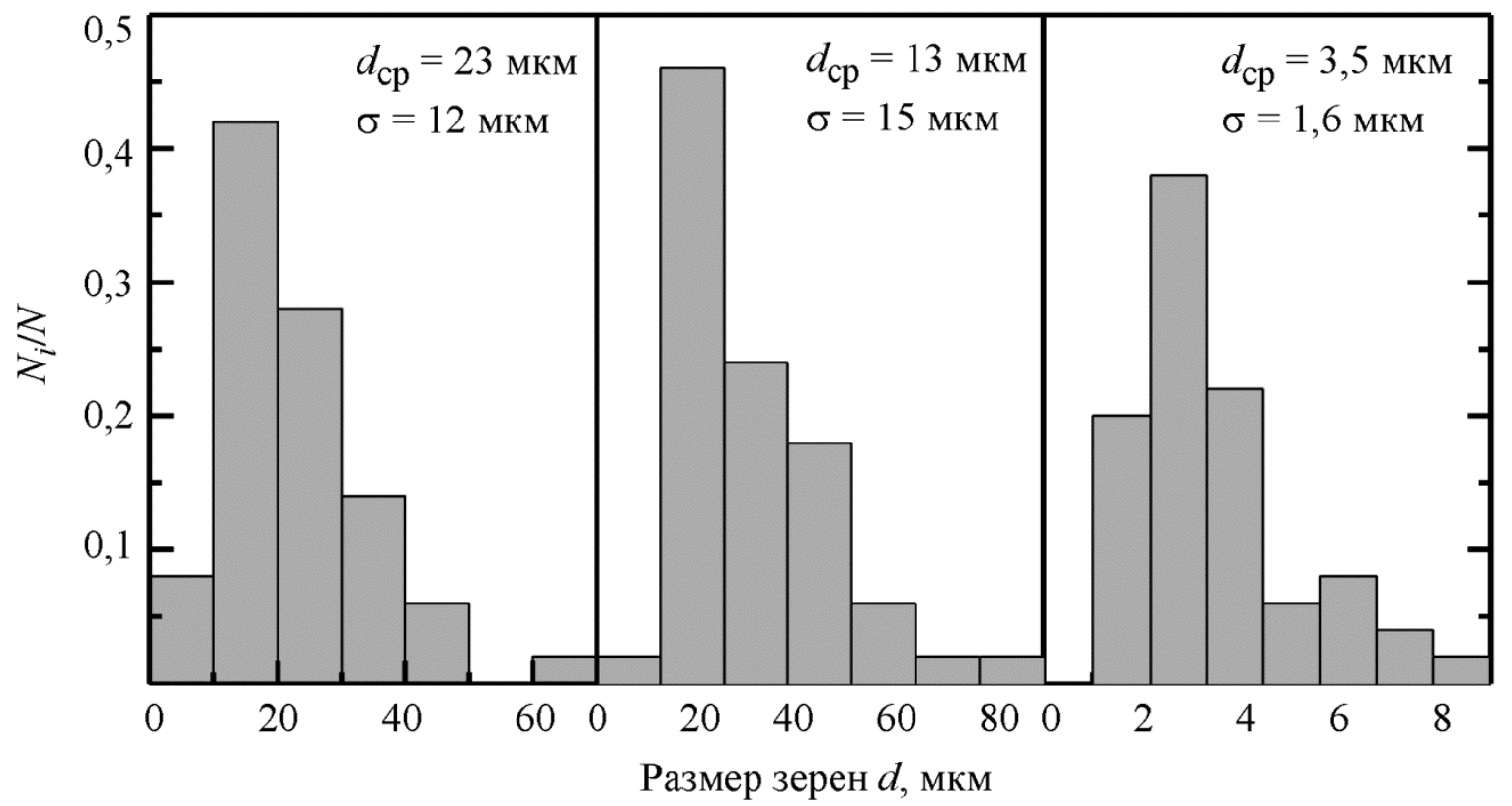

$a$ $\sigma$

B

Рис. 3. Распределения по размерам зерен в основном металле - $a$ и зонах термомеханического воздействия - $б$ и перемешивания - в СТП-соединения образца № 1

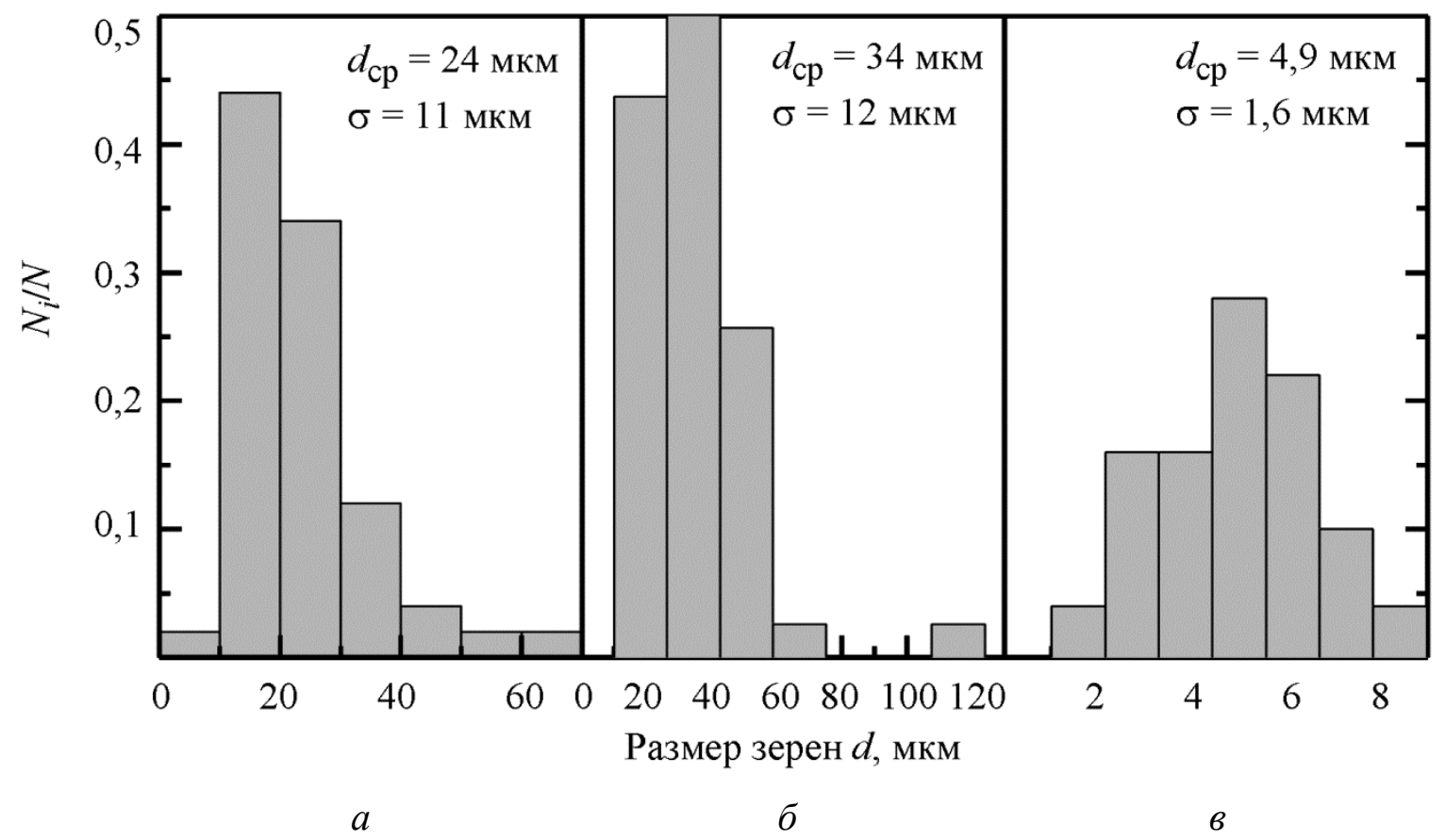

Рис. 4. Распределения по размерам зерен в основном металле - $a$ и зонах термомеханического воздействия - б и перемешивания - в СТП-соединения образца № 2 
В зоне перемешивания СТП в образце № 1 распределение по размерам зерен $\alpha$-Al твердого раствора имеет бимодальный вид. Средний размер зерна составляет $3,5 \pm 1,7$ мкм, но в распределении имеется заметный пик, соответствующий размерам зерен 6,0 мкм. Образование этого пика, возможно, связано с началом процесса динамической рекристаллизации, протекающего после измельчения зерен рабочим инструментом.

Для зоны перемешивания образца № 2 распределение по размерам зерен имеет мономодальный вид, в отличие от бимодального распределения для образца № 1, а средний размер зерна $\alpha$-Al твердого раствора смещен в область больших размеров и составляет 5,0 $\pm 1,7$ мкм. Возможно, что процесс динамической рекристаллизации измельченных рабочим инструментом зерен полностью реализовался за счет более высокой температуры в процессе СТП.

Как показали РЭМ исследования, в процессе СТП претерпевает трансформацию не только зеренная структура основного металла, но и фазовый состав в зонах влияния СТП. Рассмотрим структуру основного металла и зон влияния СТП, выявляемую при РЭМ исследовании в режиме фазового контраста (обратно рассеянных электронов).

На рис. 5 представлены оптическое и РЭМ-изображения СТП-соединения и основного металла образца № 1. В основном металле вне зон влияния СТП наблюдаются выделения вторичных фаз в виде частиц интерметаллидов различных форм и размеров (рис. 5). По морфологии различимы достаточно крупные (до 16 мкм) частицы неправильной формы, ориентированные наибольшими своими сторонами вдоль направления прокатки основного металла. Кроме того, наблюдаются более мелкие (до 5 мкм) округлые хаотически распределенные частицы и еще более мелкие (до 2 мкм) округлые ориентированные вдоль направления прокатки в виде строчек.

Как показал элементный микроанализ, крупные частицы неправильной формы (рис. 5; табл. 2; спектры 1 и 2) представляют интерметаллидные выделения системы алюминиймедь-марганец с нерастворимыми примесями в виде кремния и железа [13]. Тогда как более мелкие округлые частицы (рис. 5; табл. 2; спектр 3) представляют растворимые интерметаллидные выделения системы алюминий-медь [13]. Вероятнее всего это выделения $\theta$-фазы $\left(\mathrm{CuAl}_{2}\right)[14]$.

В зоне ТМВ выявляются выделения вторичных интерметаллидных фаз (рис. 5; табл. 2; спектры 9 и 10) с элементным составом, близким к выделениям фаз в основном металле вне зоны воздействия СТП. Отметим, что морфология выделений в зоне ТМВ претерпела трансформацию. Изменилась ориентация всех типов выделений. В зоне TMB они ориентированы вдоль направления течения металла, вызванного воздействием рабочего инструмента (рис. 5). Наиболее крупные выделения неправильной формы разбиты на близко расположенные отдельные фрагменты, наибольшие размеры которых не превышают 8,5 мкм. Размеры же округлых частиц не изменились.

В зоне перешивания (ядре СТП) наиболее крупные выделения, также как и в зоне ТМВ и в основном металле вне зоны воздействия СТП, являются нерастворимыми интерметаллидными фазами (рис. 5; табл. 2; спектр 7). Форма таких выделений близка к округлой, а размеры $\leq 8,5$ мкм. Распределены они в пределах зоны перемешивания хаотически и обособленно, без образования скоплений фрагментов, как в зоне ТМВ. Что же касается частиц вторичных выделений изначально округлой формы, то их размеры уменьшились и не превышают 1,5 мкм.

Отметим в области перемешивания большую, чем в основном металле и зоне ТМВ, плотность мелкодисперсных выделений с размерами $\leq 1,0$ мкм. Кроме того, при увеличениях более 1000 крат по границам структурных элементов выявляются выделения в виде мелкодисперсных пластин (рис. 5). По причине малого размера объектов анализа элементный состав мелкодисперсных выделений (как округлых, так и пластинчатых) корректно определить весьма затруднительно. Однако установлено, что они являются растворимыми интерметаллидными выделениями системы алюминий-медь-магний (рис. 5; табл. 2; спектр 8). 

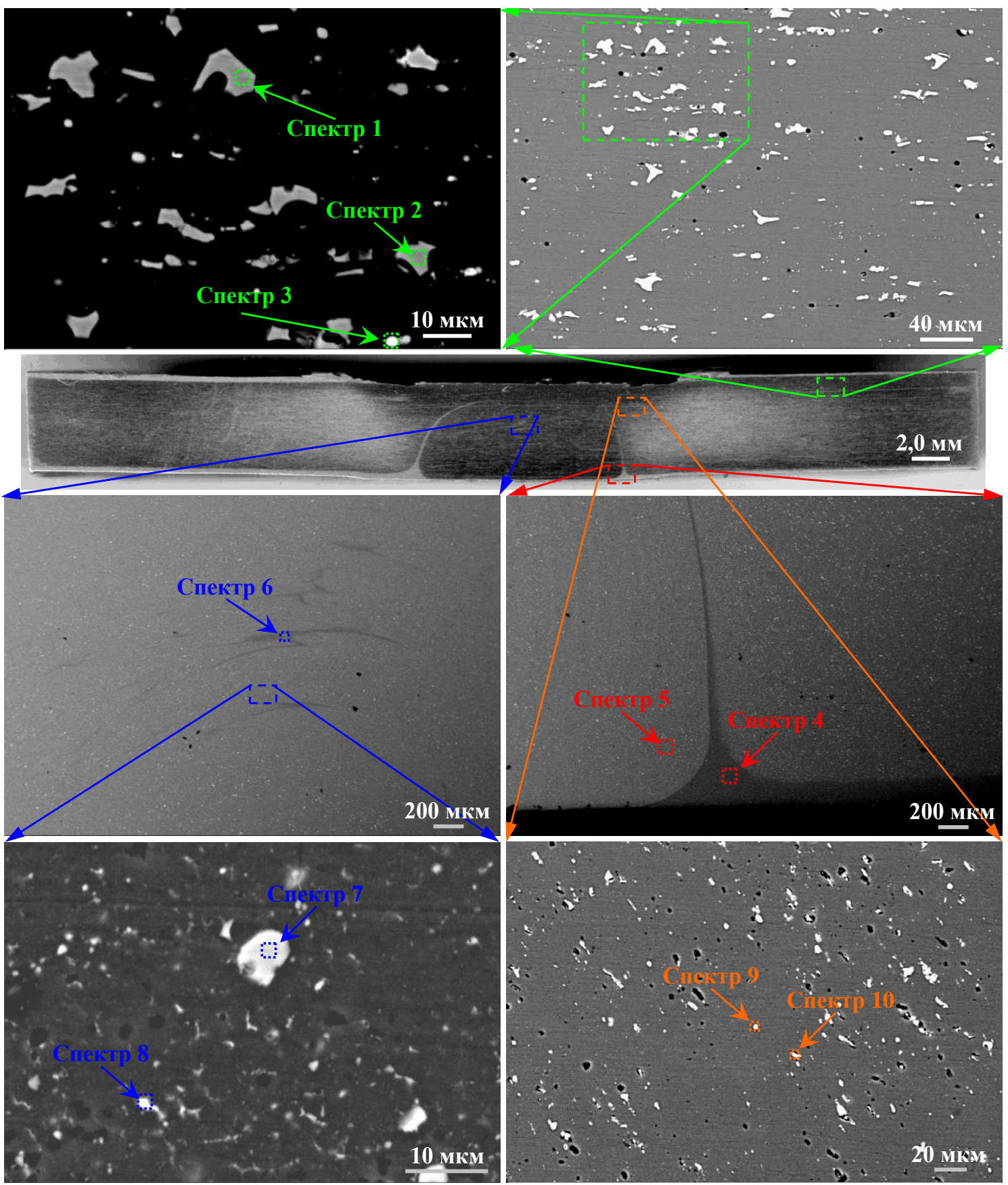

Рис. 5. Оптическое и РЭМ изображения СТП-соединения и основного металла листового проката марки Д16АТ (образец № 1). Показаны области проведения микроанализа химического состава. Полированный шлиф поперек оси СТП

Элементный состав твердого раствора как в основном металле, так во всех зонах воздействия СТП соответствует марочным значениям для сплава Д16, например, см. спектр 5 на рис. 5 и в табл. 2.

На рис. 6 представлены оптическое и РЭМ-изображения СТП-соединения и основного металла образца № 2. Как и в случае образца № 1 в зоне ТМВ выделения интерметаллидных частиц всех типов ориентированы вдоль направления течения металла, вызванного воздействием рабочего инструмента (рис. 6). Как и в образце № 1 крупные выделения неправильной формы разбиты на близко расположенные отдельные фрагменты, наибольшие размерности которых не превышают 9,0 мкм. А вот размеры округлых частиц, в отличие от частиц в 
зоне ТМВ образца № 1, уменьшились относительно исходного состояния (вне зоны влияния СТП) и составляют $(1,0-2,8)$ мкм.

Таблица 2 - Результаты микроанализа элементного состава в точках (рис. 5)

\begin{tabular}{|c|c|c|c|c|c|c|c|}
\hline \multicolumn{2}{|c|}{$\begin{array}{c}\text { Область } \\
\text { микроанализа }\end{array}$} & \multicolumn{6}{|c|}{ Содержание химических элементов, \% вес. (атом) } \\
\hline $\begin{array}{l}\text { Маркировка } \\
\text { спектра }\end{array}$ & Зона & $\mathrm{Si}$ & $\mathrm{Fe}$ & $\mathrm{Cu}$ & Mn & $\mathrm{Mg}$ & $\mathrm{Al}$ \\
\hline Спектр 1 & \multirow{3}{*}{$\begin{array}{c}\text { Основной } \\
\text { металл }\end{array}$} & $\begin{array}{c}5,53 \\
(6,59)\end{array}$ & $\begin{array}{c}18,51 \\
(11,29)\end{array}$ & $\begin{array}{l}10,09 \\
(5,41)\end{array}$ & $\begin{array}{l}10,30 \\
(6,39)\end{array}$ & - & $\begin{array}{c}55,68 \\
(70,32)\end{array}$ \\
\hline Спектр 2 & & $\begin{array}{c}5,31 \\
(6,46)\end{array}$ & $\begin{array}{c}16,87 \\
(10,32)\end{array}$ & $\begin{array}{l}11,94 \\
(6,42)\end{array}$ & $\begin{array}{l}10,28 \\
(6,40)\end{array}$ & - & $\begin{array}{c}55,60 \\
(70,41)\end{array}$ \\
\hline Спектр 3 & & - & - & $\begin{array}{c}46,37 \\
(26,82)\end{array}$ & - & $\begin{array}{c}0,82 \\
(1,24)\end{array}$ & $\begin{array}{c}52,81 \\
(71,94)\end{array}$ \\
\hline Спектр 4 & Плакировка & - & - & - & - & - & $\begin{array}{c}100,00 \\
(100,00)\end{array}$ \\
\hline Спектр 5 & $\begin{array}{c}\text { Перемешивания } \\
\text { вблизи } \\
\text { плакировки } \\
\end{array}$ & - & - & $\begin{array}{c}4,96 \\
(2,20)\end{array}$ & $\begin{array}{c}0,78 \\
(0,40)\end{array}$ & $\begin{array}{c}1,25 \\
(1,45)\end{array}$ & $\begin{array}{c}91,61 \\
(95,59)\end{array}$ \\
\hline Спектр 6 & \multirow{3}{*}{$\begin{array}{c}\text { Перемешивания } \\
\text { в центре }\end{array}$} & - & - & - & - & - & $\begin{array}{c}100,00 \\
(100,00)\end{array}$ \\
\hline Спектр 7 & & $\begin{array}{c}4,88 \\
(6,00)\end{array}$ & $\begin{array}{c}17,47 \\
(10,79)\end{array}$ & $\begin{array}{l}14,61 \\
(7,95)\end{array}$ & $\begin{array}{c}8,53 \\
(5,37)\end{array}$ & - & $\begin{array}{c}54,55 \\
(69,89) \\
\end{array}$ \\
\hline Спектр 8 & & - & - & $\begin{array}{c}29,92 \\
(15,36)\end{array}$ & $\begin{array}{c}0,48 \\
(0,25)\end{array}$ & $\begin{array}{c}1,37 \\
(1,84)\end{array}$ & $\begin{array}{c}62,29 \\
(82,55)\end{array}$ \\
\hline Спектр 9 & \multirow{2}{*}{$\begin{array}{c}\text { Термо- } \\
\text { механического } \\
\text { воздействия }\end{array}$} & - & - & $\begin{array}{c}45,24 \\
(25,94)\end{array}$ & - & $\begin{array}{c}0,94 \\
(1,41)\end{array}$ & $\begin{array}{c}53,81 \\
(72,65)\end{array}$ \\
\hline Спектр 10 & & $\begin{array}{c}4,66 \\
(5,59) \\
\end{array}$ & $\begin{array}{c}15,14 \\
(9,15)\end{array}$ & $\begin{array}{l}13,82 \\
(7,34)\end{array}$ & $\begin{array}{c}7,96 \\
(4,89)\end{array}$ & - & $\begin{array}{c}58,42 \\
(73,04)\end{array}$ \\
\hline \multicolumn{2}{|c|}{$\begin{array}{c}\text { Сплав Д16 (1160) } \\
\text { по ГОСТ } 4784 \text { [15] }\end{array}$} & $\leq 0,50$ & $\leq 0,50$ & $3,8-4,9$ & $0,3-0,9$ & $1,2-1,8$ & Основа \\
\hline
\end{tabular}

Результаты элементного микроанализа свидетельствуют, что фрагменты крупных частиц неправильной формы (рис. 6; табл. 3; спектры 5 и 6), как и у образца № 1, представляют интерметаллидные выделения системы алюминий-медь-марганец с нерастворимыми примесями в виде кремния и железа. Но, в отличие от подобных частиц в образце № 1, фрагменты раздробленных крупных частиц обеднены марганцем и примесями - кремнием и железом. Мелкие округлые частицы (рис. 6; табл. 3; спектр 7) представляют растворимые интерметаллидные выделения системы алюминий-медь [13] и близки по составу округлым мелким частицам в основном металле вне зоны влияния СТП, а также в зоне ТМВ образца № 1 .

Из сравнения микроструктуры зон перешивания образцов № 1 и 2 отметим следующие общие особенности и различия. Как и в случае образца № 1, крупные выделения в зоне ТМВ и в основном металле являются нерастворимыми в условиях сварки трением с перемешиванием интерметаллидными фазами (рис. 6; табл. 3; спектры 1 и 2). Форма таких выделений близка к округлой. Распределены они в пределах зоны перемешивания хаотически и обособленно, без образования скоплений фрагментов как в зоне ТМВ. Размеры этих выделений не превышают 10 мкм и практически равны размерам аналогичных частиц в образце № 1 . 

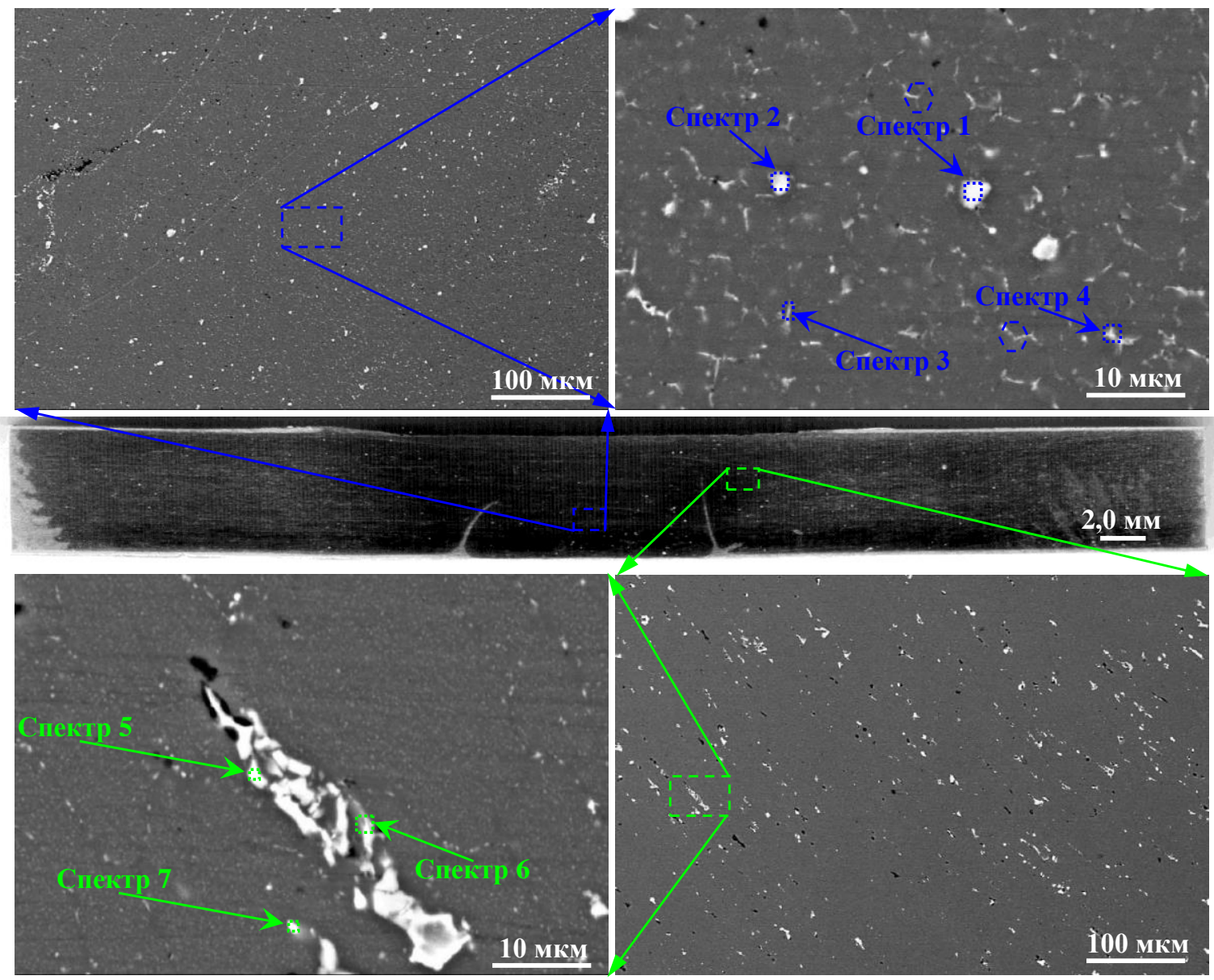

Рис. 6. Оптическое и РЭМ изображения СТП-соединения и основного металла листового проката марки Д16АТ (образец № 2). Показаны области проведения микроанализа химического состава. Полированный шлиф поперек оси соединения и направления прокатки основного металла

Размеры частиц выделений изначально округлой формы также уменьшились по сравнению с исходным состоянием основного металла (вне зоны воздействия СТП) и не превышают 0,6 мкм. Аналогичные частицы в образце № 1 имеют более крупные размеры до 1,5 мкм.

Как и для образца № 1 имеют место высокая плотность мелких выделений (с размерами не более 0,12 мкм) и пластинчатые выделения по границам структурных элементов. По элементному составу оба типа этих выделений соответствуют интерметаллидным соединениям $\mathrm{Al}_{2} \mathrm{CuMg}+\mathrm{CuAl}_{2}$ (рис. 6; табл. 3; спектр 3). Выделения по границам структурных элементов более крупные и протяженные чем в образце № 1 и в ряде случаев декорируют тройные стыки структурных элементов. В качестве примера на верхней правой выноске рис. 6 два таких стыка выделены штриховыми замкнутыми линиями в виде правильных шестигранников. 
Таблица 3 - Результаты микроанализа элементного состава в точках (рис. 6)

\begin{tabular}{|c|c|c|c|c|c|c|c|}
\hline \multicolumn{2}{|c|}{$\begin{array}{c}\text { Область } \\
\text { микроанализа }\end{array}$} & \multicolumn{6}{|c|}{ Содержание химических элементов, \% вес. (атом) } \\
\hline $\begin{array}{c}\text { Маркировка } \\
\text { спектра }\end{array}$ & Зона & $\mathrm{Si}$ & $\mathrm{Fe}$ & $\mathrm{Cu}$ & Mn & $\mathrm{Mg}$ & $\mathrm{Al}$ \\
\hline Спектр 1 & \multirow{4}{*}{$\begin{array}{c}\text { Перемешивания } \\
\text { в центре }\end{array}$} & $\begin{array}{c}3,81 \\
(4,26)\end{array}$ & $\begin{array}{l}11,75 \\
(6,61)\end{array}$ & $\begin{array}{c}7,93 \\
(3,92)\end{array}$ & $\begin{array}{c}6,64 \\
(3,79)\end{array}$ & $\begin{array}{c}0,64 \\
(0,82)\end{array}$ & $\begin{array}{c}69,25 \\
(80,60)\end{array}$ \\
\hline Спектр 2 & & $\begin{array}{c}3,28 \\
(3,54)\end{array}$ & $\begin{array}{c}7,56 \\
(4,10)\end{array}$ & $\begin{array}{c}7,09 \\
(3,38)\end{array}$ & $\begin{array}{c}5,61 \\
(3,09)\end{array}$ & $\begin{array}{c}0,78 \\
(0,97)\end{array}$ & $\begin{array}{c}75,87 \\
(84,92)\end{array}$ \\
\hline Спектр 3 & & - & - & $\begin{array}{c}8,80 \\
(3,93) \\
\end{array}$ & - & $\begin{array}{c}1,44 \\
(1,68)\end{array}$ & $\begin{array}{r}89,77 \\
(94,40) \\
\end{array}$ \\
\hline Спектр 4 & & $\begin{array}{c}0,65 \\
(0,69)\end{array}$ & - & $\begin{array}{l}13,51 \\
(6,34)\end{array}$ & $\begin{array}{c}3,71 \\
(2,02)\end{array}$ & $\begin{array}{c}1,64 \\
(2,01)\end{array}$ & $\begin{array}{r}80,49 \\
(88,95) \\
\end{array}$ \\
\hline Спектр 5 & \multirow{3}{*}{$\begin{array}{c}\text { Термо- } \\
\text { механического } \\
\text { воздействия }\end{array}$} & $\begin{array}{c}3,34 \\
(3,79)\end{array}$ & $\begin{array}{l}10,90 \\
(6,23)\end{array}$ & $\begin{array}{l}10,82 \\
(5,43)\end{array}$ & $\begin{array}{c}6,76 \\
(3,92)\end{array}$ & - & $\begin{array}{c}68,18 \\
(80,62)\end{array}$ \\
\hline Спектр 6 & & $\begin{array}{c}1,28 \\
(1,48)\end{array}$ & $\begin{array}{c}8,93 \\
(5,19)\end{array}$ & $\begin{array}{l}17,14 \\
(8,76)\end{array}$ & $\begin{array}{c}4,65 \\
(2,75)\end{array}$ & - & $\begin{array}{c}67,99 \\
(81,82) \\
\end{array}$ \\
\hline Спектр 7 & & - & - & $\begin{array}{c}46,41 \\
(26,86)\end{array}$ & - & $\begin{array}{c}0,62 \\
(0,93)\end{array}$ & $\begin{array}{c}52,97 \\
(72,20)\end{array}$ \\
\hline
\end{tabular}

\section{4. Заключение}

По результатам структурных исследований СТП-соединений листового проката марки Д16АТ по режимам № 1 и 2 выявлены основные особенности влияния параметров процесса сварки трением с перемешиванием на структуру листового проката марки Д16АТ. Обнаружено, что помимо изменений в зеренной структуре $\alpha$-Al твердого раствора происходят изменения и в процессе выделения частиц интерметаллидных фаз, что прослеживается в морфологии, среднем размере и химическим составе частиц интерметаллидных фаз различной природы в образцах, обработанных по разным технологическим режимам СТП. Изменение морфологии частиц вторичных фаз обусловлено различием термомеханического воздействия в разных зонах влияния СТП.

Повышенные значения среднего размера зерна $\alpha$-Al твердого раствора в зоне перемешивания, по сравнению с результатами авторов других работ, связаны прежде всего с высокой температурой формирования соединения и, как следствие, высокой степенью рекристаллизации. Также с высокой температурой формирования соединения связано большое количество выделений вторичных фаз в объеме зоны перемешивания.

\section{Благодарность}

Работа выполнена в рамках ПФНИ ГАН на 2013-2020 годы, направление III.23 и при финансовой поддержке РФФИ, проект р_а №16-48-700652.

\section{Литература}

1. Бойцов А. Г., Качко В. В., Курицын Д. Н. Сварка трением перемешиванием // РИТМ Машиностроения. - 2013. - № 10 (88). - C. 38-44. - URL: http://ritmmagazine.ru/ru/magazines/2013/ritm-10-88-2013\#page-4142. (Дата обращения: 25.04.2018). 2. Миронов С. Ю. Формирование зеренной структуры при сварке трением с перемешиванием // Физическая мезомеханика. - 2014. - Т. 17, № 1. - С.103-113.

3. Миронов С. Ю. Кристаллографические текстуры, формирующиеся при сварке трением с перемешиванием // Физическая мезомеханика. - 2014. - Т. 17, № 2. - С. 43-54. 
4. Friction Stir Welded Butt Joints of AA2024 T3 and AA7075 T6 Aluminum Alloys. / P. Avinash, M. Manikandan, N. Arivazhagan, Ramkumar K. Devendranath, S. Narayanan // Procedia Engineering. - 2014. - Vol. 75. - P. 98-102. - DOI: 10.1016/j.proeng.2013.11.020.

5. Khodir S. A., Shibayanagi T. Microstructure and Mechanical Properties of Friction Stir Welded Dissimilar Aluminum Joints of AA2024-T3 and AA7075-T6 // Materials Transactions. 2007. - Vol. 48, no. 7. - P. 1928-1937. - DOI: 10.2320/matertrans.MRA2007042.

6. Khodir S. A., Shibayanagi T. Microstructure and Mechanical Properties of Friction Stir Welding Similar and Dissimilar Joints of Al and Mg alloys // Transactions of JWRI. - 2007. Vol. 36. - No. 1. - P. 27-40.

7. Friction-stir welding of ultra-fine grained sheets of $\mathrm{Al}-\mathrm{Mg}-\mathrm{Sc}-\mathrm{Zr}$ alloy / S. Malopheyev, S. Mironov, V. Kulitskiy, R. Kaibyshev // Materials Science \& Engineering A. - 2015. - Vol. 624. P. 132-139. - DOI: 10.1016/j.msea.2014.11.079.

8. ГОСТ 21631-76. Листы из алюминия и алюминиевых сплавов. Технические условия. Москва : Стандаринформ, 2008.

9. Муравьёв В. И., Бахматов П. В., Мелкоступов К. А. К вопросу актуальности исследования сварки трением с перемешиванием конструкций из высокопрочныхалюминиевых сплавов // Ученые записки Комсомольского-на-Амуре государственного технического университета. - 2010. - № II-1 (2). - С. 110-125.

10. Баранова Л. В., Демина Э. Л. Металлографическое травление металлов и сплавов. Справочник. - М. : Металлургия, 1986. - 256 с.

11. Салтыков С. А. Стереометрическая металлография. - М. : Металлургия, 1976. - 271 с.

12. ОСТ 134-1051-2010. Сварка фрикционная. Технические требования к сварным соединениям. - М. : Федеральное космическое агентство. -26 с.

13. Мондольфо Л.Ф. Структура и свойства алюминиевых сплавов / пер. с англ. под ред. Ф. И. Квасова, Г. Б. Строганова, И. Н. Фридляндера. - М.: Металлургия, 1979. - 640 с.

14. Fortuna S., Kalashnikova T., Kolubaev E. Structural and Phase State Evolution in Friction Drilling on AA2024 // AIP Conference Proceedings. - 2017. - Vol. 1909. - P. 020055. DOI: $10.1063 / 1.5013736$.

15. ГОСТ 4784-97 Алюминий и сплавы алюминиевые деформируемые. Марки / взамен 4784-74 ; введ. 2000-07-01. - М. : ИПК Издательство стандартов, 1999. - 32 с. 